\title{
Article \\ Systematic Assessment of Chemokine Signaling at Chemokine Receptors CCR4, CCR7 and CCR10
}

\author{
Herman D. Lim ${ }^{1,2}\left(\right.$, J. Robert Lane ${ }^{3,4}\left(\mathbb{D}\right.$, Meritxell Canals ${ }^{3,4}$ and Martin J. Stone ${ }^{1,2, * \mathbb{C}}$ \\ 1 Infection and Immunity Program, Monash Biomedicine Discovery Institute, Clayton, VIC 3800, Australia; \\ herman.d.lim@gmail.com \\ 2 Department of Biochemistry and Molecular Biology, Monash University, Clayton, VIC 3800, Australia \\ 3 Division of Physiology, Pharmacology and Neuroscience, School of Life Sciences, Queen's Medical Centre, \\ University of Nottingham, Nottingham NG7 2UH, UK; rob.lane@nottingham.ac.uk (J.R.L.); \\ meritxell.canals@nottingham.ac.uk (M.C.) \\ 4 Centre of Membrane Protein and Receptors, Universities of Birmingham and Nottingham, \\ Nottingham NG7 2UH, UK \\ * Correspondence: martin.stone@monash.edu; Tel.: +61-3-9902-9246
}

Citation: Lim, H.D.; Lane, J.R.; Canals, M.; Stone, M.J. Systematic Assessment of Chemokine Signaling at Chemokine Receptors CCR4, CCR7 and CCR10. Int. J. Mol. Sci. 2021, 22, 4232. https://doi.org/10.3390/ ijms22084232

Academic Editor: Alain Couvineau

Received: 31 March 2021

Accepted: 15 April 2021

Published: 19 April 2021

Publisher's Note: MDPI stays neutral with regard to jurisdictional claims in published maps and institutional affiliations.

Copyright: (c) 2021 by the authors. Licensee MDPI, Basel, Switzerland. This article is an open access article distributed under the terms and conditions of the Creative Commons Attribution (CC BY) license (https:// creativecommons.org/licenses/by/ $4.0 /)$.

\begin{abstract}
Chemokines interact with chemokine receptors in a promiscuous network, such that each receptor can be activated by multiple chemokines. Moreover, different chemokines have been reported to preferentially activate different signalling pathways via the same receptor, a phenomenon known as biased agonism. The human CC chemokine receptors (CCRs) CCR4, CCR7 and CCR10 play important roles in $\mathrm{T}$ cell trafficking and have been reported to display biased agonism. To systematically characterize these effects, we analysed $G$ protein- and $\beta$-arrestin-mediated signal transduction resulting from stimulation of these receptors by each of their cognate chemokine ligands within the same cellular background. Although the chemokines did not elicit ligand-biased agonism, the three receptors exhibited different arrays of signaling outcomes. Stimulation of CCR4 by either CC chemokine ligand 17 (CCL17) or CCL22 induced $\beta$-arrestin recruitment but not G protein-mediated signaling, suggesting that CCR4 has the potential to act as a scavenger receptor. At CCR7, both CCL19 and CCL21 stimulated G protein signaling and $\beta$-arrestin recruitment, with CCL19 consistently displaying higher potency. At CCR10, CCL27 and CCL28(4-108) stimulated both G protein signaling and $\beta$-arrestin recruitment, whereas CCL28(1-108) was inactive, suggesting that CCL28(4-108) is the biologically relevant form of this chemokine. These comparisons emphasize the intrinsic abilities of different receptors to couple with different downstream signaling pathways. Comparison of these results with previous studies indicates that differential agonism at these receptors may be highly dependent on the cellular context.
\end{abstract}

Keywords: chemokine; chemokine receptor; CCR4; CCR7; CCR10; GPCR; signaling pathways; partial agonism; biased agonism

\section{Introduction}

Chemokines (chemotactic cytokines) and their receptors are the key regulators of leukocyte recruitment in both normal immune function and numerous inflammatory diseases [1,2]. Chemokine receptors are expressed on different types of leukocytes and signal in response to chemokine binding, giving rise to regulation of leukocyte adhesion and chemotaxis to sites of high chemokine expression. The chemokine ligands and chemokine receptors interact in a complex network, such that most chemokines activate multiple receptors and most receptors respond to multiple chemokines. In humans, there are $\sim 43$ chemokines and $\sim 19$ receptors, which belong to the family of $G$ protein-coupled receptors (GPCRs) that signal via heterotrimeric $G$ proteins and non-G protein effectors, such as $\beta$-arrestins. Typically, $G$ protein activation via chemokine receptors promotes chemotaxis of the receptor-expressing cells. In contrast, several "decoy" chemokine receptors have 
been identified that are not coupled to $G$ proteins but still interact with $\beta$-arrestins, leading to internalization of the chemokine receptor-chemokine ligand complex (thereby acting as chemokine sinks) [3].

In some cases, different chemokines can activate the same receptor but elicit distinct signaling responses. Such differences are classified as biased agonism if the ligands differ in their relative efficiencies of signaling via two alternative pathways, e.g., G protein versus $\beta$-arrestin pathways, or pathways mediated by different $G$ protein subtypes. Biased agonism has been reported for several chemokine receptors, including CCR1, CCR2, CCR4, CCR5, CCR7, CCR10, CXCR2 and CXCR3 [4-9]. Biased agonism is distinct from differences in intrinsic efficacy (or partial agonism), which applies to ligands that activate the same pathways but differ in the relative magnitude of the signaling outcomes. For example, we have previously characterized partial agonism at the chemokine receptor CCR2 [10].

Among the chemokine receptors previously reported to exhibit biased agonism are CCR4, CCR7 and CCR10, all of which play key roles in trafficking of T cells, thus contributing to normal $\mathrm{T}$ cell selection, immune responses to viral infection, and/or allergic or auto-immune reactions. Each of these receptors has two cognate chemokine ligands [1]. CCR4 activation by CCL17 and CCL22 is primarily thought to regulate the migration of T helper type $2\left(\mathrm{~T}_{\mathrm{h}} 2\right)$ cells during the process of $\mathrm{T}$ cell selection as well as during allergic responses (e.g., asthma and atopic dermatitis) but may also be involved in recruitment of regulatory $\mathrm{T}$ cells and certain subsets of monocytes and dendritic cells (DCs) [11,12]. CCR7 is expressed on various types of T cells, B cells and DCs that migrate to (or within) lymphoid organs, in which the two CCR7 ligands, CCL19 and CCL21, are expressed [13]. CCR10 is expressed on both T and B cells. Activation of CCR10 by CCL27 promotes the recruitment of $\mathrm{T}$ lymphocytes to the skin, whereas CCR10 activation by CCL28 stimulates trafficking of immunoglobulin A antibody-secreting plasma cells (B lymphocytes) to mucosal tissues, including intestines, lung, nasal cavity, uterus and lactating mammary gland [14].

A number of previous studies have investigated the possibility that cognate chemokines differentially activate CCR4, CCR7 and CCR10, with potential implications for regulation of lymphocyte trafficking and selection. In the case of CCR4, CCL22 was observed to be more effective than CCL17 at inducing receptor internalization $[15,16]$ and activation by the two ligands was affected differently by receptor mutations or inhibitory antibodies [17]. Similarly, for CCR7, several studies have found that CCL19 was more effective than CCL21 at inducing receptor internalization and $\beta$-arrestin recruitment [7-9,18-21]. However, these studies came to different conclusions regarding whether the two ligands stimulate equivalent $G$ protein-mediated responses via CCR7 [7-9,21]. In the only study investigating differential agonism at CCR10, Rajagopal et al. [4] reported that both CCL27 and CCL28 effectively stimulated G protein-mediated signaling, whereas only CCL27 was able to simulate $\beta$-arrestin recruitment. Considering the apparent importance of differential agonism at these chemokine receptors in regulation of immune cell function, we were interested in identifying the molecular features of both the chemokines and receptors that contribute to these differences in receptor activation. As a prelude to such studies, we undertook a systematic evaluation of differential activation of CCR4, CCR7 and CCR10 by their cognate chemokine ligands. Herein, we report our findings and discuss both similarities and differences amongst these receptors and compared to previous reports.

\section{Results}

\subsection{Cognate Chemokines Stimulate $\beta$-Arrestin Recruitment at CCR4, CCR7 and CCR10}

Activation of chemokine receptors typically induces $G$ protein receptor kinase (GRK)mediated phosphorylation of the receptor $C$-terminal region and recruitment of $\beta$-arrestins to the phosphorylated receptor, leading to receptor internalization [22]. To detect $\beta$-arrestin recruitment to CCR4, CCR7 and CCR10, we used Chinese hamster ovary (CHO) cells transiently transfected to express each receptor and $\beta$-arrestin2, tagged with a bioluminescence resonance energy transfer (BRET) donor and acceptor, respectively (Figure 1a). 
Treatment of these cells with cognate chemokines of the expressed receptors stimulated concentration-dependent $\beta$-arrestin2 recruitment (Figure $1 \mathrm{~b}-\mathrm{d}$ ).

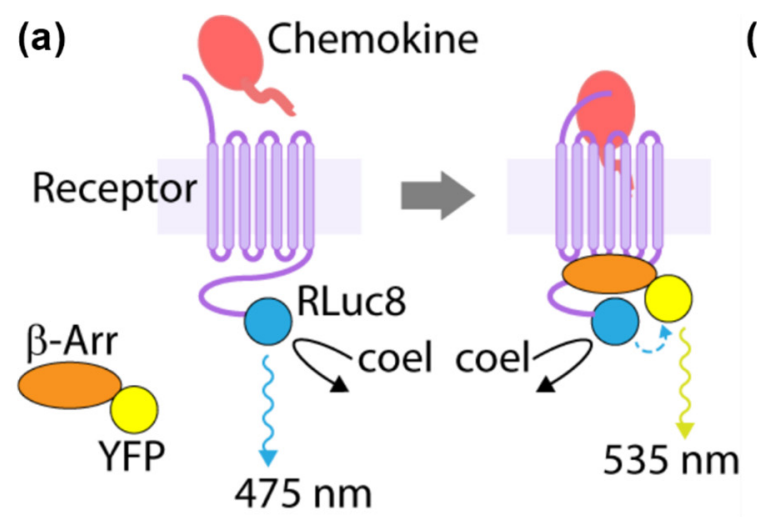

(c)

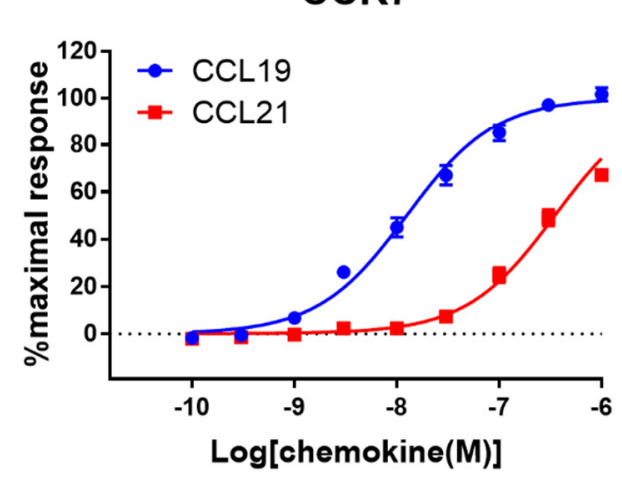

(b)

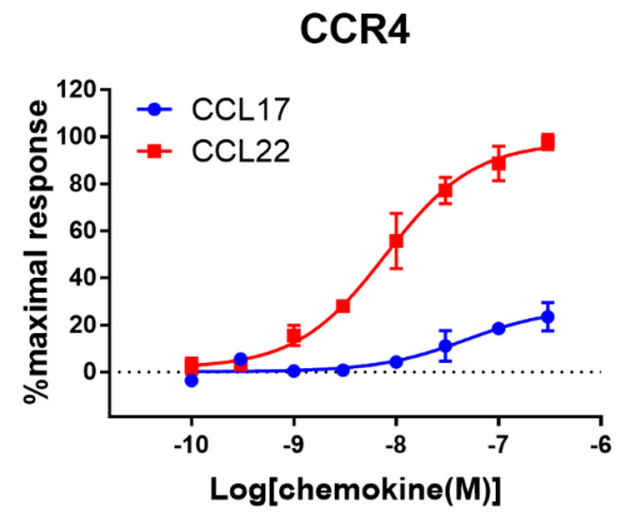

(d)

\section{CCR10}

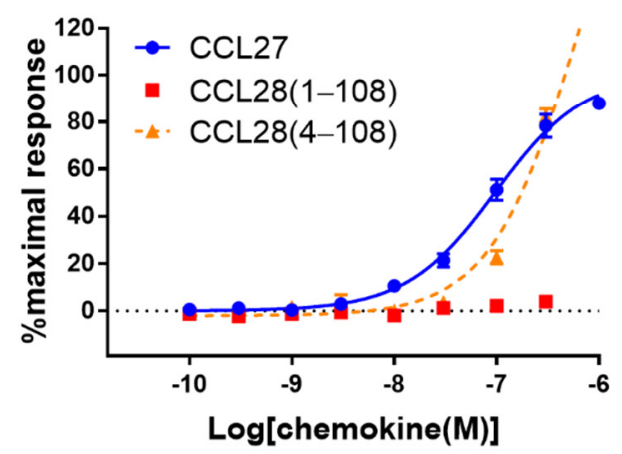

Figure 1. Chemokine ligands differentially stimulate $\beta$-arrestin recruitment to CCR4, CCR7 and CCR10. (a) The principle of the BRET-based $\beta$-arrestin recruitment assay. The Renilla luciferase (RLuc8) is fused at the C-termini of the receptors and the yellow fluorescent protein (YFP) tagged at the $\mathrm{N}$-terminus of $\beta$-arrestin2 ( $\beta$-Arr). Upon activation by a chemokine agonist, YFP- $\beta$-arrestin2 is recruited to the receptor, bringing the YFP and RLuc8 into close proximity and enabling the resonance energy transfer after addition of the RLuc8 substrate coelenterazine $h$ (coel). (b-d) Chemokine-induced $\beta$-arrestin recruitment at (b) CCR4, (c) CCR7, and (d) CCR10. A dashed line of best fit is shown in the case that the signal does not reach saturation. The presented data are mean \pm SEM of at least three independent experiments, each performed in triplicate.

For $\beta$-arrestin recruitment to CCR4, CCL22 stimulated a 3.5-fold higher maximal response $\left(E_{\max }\right)$ than CCL17 (Figure $1 \mathrm{~b}$ and Table 1). CCL22 also appeared to have higher potency than CCL17 ( $p E C_{50}$ values of $8.1 \pm 0.1$ and $7.3 \pm 0.3$, respectively), although this was not significant.

At CCR7, both CCL19 and CCL21 stimulated robust $\beta$-arrestin recruitment responses. However, the potency was approximately 20 -fold higher for CCL19 ( $p E C_{50}$ values of $7.9 \pm 0.1$ and $6.7 \pm 0.1$, respectively, assuming the same $E_{\max }$ value) and the CCL21 response was not saturated at the highest concentration tested (Figure 1c and Table 1). 
Table 1. Potencies and maximal effects of cognate chemokines at CCR4, CCR7 and CCR10 ${ }^{1}$.

\begin{tabular}{|c|c|c|c|c|}
\hline Receptor & Assay & Ligand & $\begin{array}{c}\text { Potency } \\
p E C_{50} \pm \mathrm{SE}^{1} \\
\left(E C_{50} \text { in } n M\right)\end{array}$ & $\begin{array}{l}\text { Maximal Effect (\%) } \\
E_{\max } \pm \mathrm{SE}^{1}\end{array}$ \\
\hline \multirow[t]{6}{*}{ CCR4 } & \multirow[t]{2}{*}{$\beta$-arrestin recruitment } & CCL17 & $7.31 \pm 0.32(48)$ & $28 \pm 6^{* *}$ \\
\hline & & CCL22 & $8.11 \pm 0.10(8)$ & 100 \\
\hline & \multirow[t]{2}{*}{$\mathrm{G}$ protein activation } & CCL17 & ND & ND \\
\hline & & CCL22 & ND & ND \\
\hline & \multirow[t]{2}{*}{ cAMP inhibition } & CCL17 & ND & ND \\
\hline & & CCL22 & ND & ND \\
\hline \multirow[t]{6}{*}{ CCR7 } & \multirow[t]{2}{*}{$\beta$-arrestin recruitment } & CCL19 & $7.93 \pm 0.06(12)$ & 100 \\
\hline & & CCL21 & $6.45 \pm 0.03(352) * * *$ & $100\left({ }^{2}\right)$ \\
\hline & \multirow[t]{2}{*}{$\mathrm{G}$ protein activation } & CCL19 & $8.71 \pm 0.09(2)$ & 100 \\
\hline & & CCL21 & $7.54 \pm 0.05(29)^{* * *}$ & $103 \pm 3$ \\
\hline & \multirow[t]{2}{*}{ cAMP inhibition } & CCL19 & $8.81 \pm 0.12(2)$ & 100 \\
\hline & & CCL21 & $7.84 \pm 0.16(14) *$ & $99 \pm 6$ \\
\hline \multirow[t]{12}{*}{ CCR10 } & \multirow[t]{3}{*}{$\beta$-arrestin recruitment } & CCL27 & $7.01 \pm 0.06(97)$ & 100 \\
\hline & & CCL28(1-108) & ND & ND \\
\hline & & CCL28(4-108) & ND & $82\left({ }^{3}\right)$ \\
\hline & \multirow[t]{3}{*}{$\mathrm{G}$ protein activation } & CCL27 & $7.66 \pm 0.05(22)$ & 100 \\
\hline & & CCL28(1-108) & ND & ND \\
\hline & & CCL28(4-108) & $6.92 \pm 0.14(121)$ & $80\left(^{3}\right)$ \\
\hline & \multirow[t]{3}{*}{ cAMP inhibition } & CCL27 & $7.27 \pm 0.10(54)$ & 100 \\
\hline & & CCL28(1-108) & ND & ND \\
\hline & & CCL28(4-108) & $6.82 \pm 0.23(152)$ & $64\left({ }^{3}\right)$ \\
\hline & \multirow[t]{3}{*}{$\mathrm{NFAT} \mathrm{Ca}^{2+}$ reporter } & CCL27 & $8.24 \pm 0.12(6)$ & 100 \\
\hline & & CCL28(1-108) & ND & ND \\
\hline & & CCL28(4-108) & $7.18 \pm 0.10(65)^{* *}$ & $106 \pm 8$ \\
\hline
\end{tabular}

${ }^{1} p E C_{50}$ values are the negative $\log$ of $E C_{50}$, in molar units. The corresponding $E C_{50}$ values (in $\mathrm{nM}$ ) are shown in parentheses. $E_{\max }$ values are relative to the reference ligand (CCL22, CCL19, or CCL27 at CCR4, CCR7, or CCR10, respectively). ND, not determinable from the experimental data (see Figures 1-3). Data are mean \pm SEM of at least three independent experiments, performed each in triplicate. ${ }^{*} p<0.05,{ }^{* *} p<0.01,{ }^{* * *} p<0.001$, relative to the reference ligand at the same receptor. Statistical analysis was performed using one-way ANOVA with Holm-Sidak's multiple-comparison. ${ }^{2}$ This $E_{\max }$ value was constrained to be the same as that of the reference ligand; the corresponding $p E C_{50}$ value is influenced by this assumption. ${ }^{3}$ These $E_{\max }$ values listed are the maximum signals observed as the curves did not reach saturation.

At CCR10, CCL27 exhibited robust $\beta$-arrestin recruitment (Figure 1d and Table 1). We also tested the two commercially available forms of CCL28. Like other chemokines, CCL28 is initially expressed with an N-terminal signal peptide, which is then proteolytically removed to yield the mature chemokine. Due to the ambiguity of predicting signal peptide cleavage sites, CCL28 is available from different suppliers as the "full-length" form, CCL28(1-108), or a form truncated by three N-terminal residues, CCL28(4-108). We observed that CCL28(1-108) does not significantly stimulate $\beta$-arrestin recruitment at CCR10, whereas the shorter form, CCL28(4-108), gave rise to robust, concentration-dependent $\beta$-arrestin recruitment (Figure 1d and Table 1). However, since the CCL28(4-108) response was not saturated at the highest concentration tested, we cannot determine whether its potency or maximal response is significantly different from that of CCL27. 


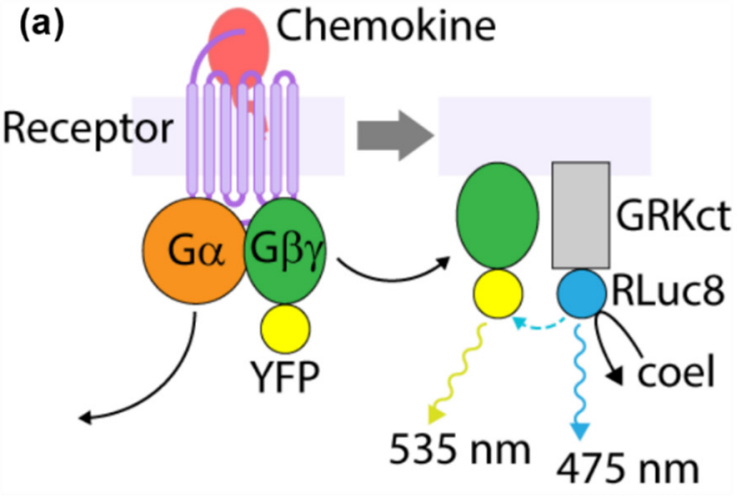

(c)

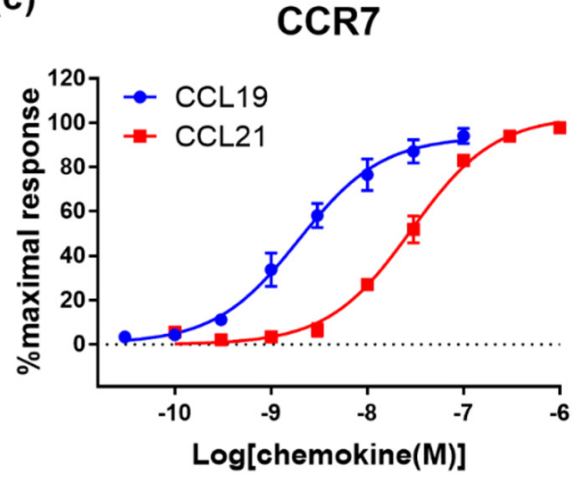

(b)

CCR4

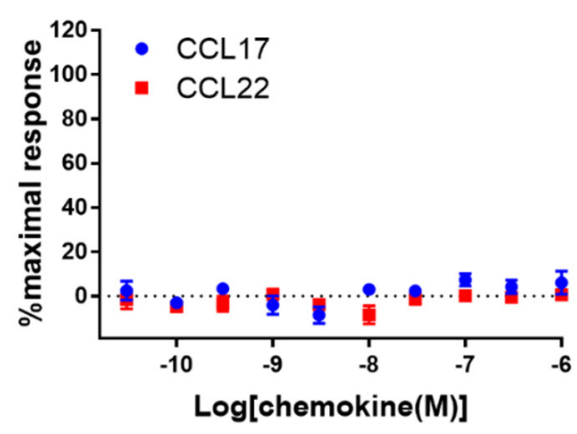

(d)

\section{CCR10}

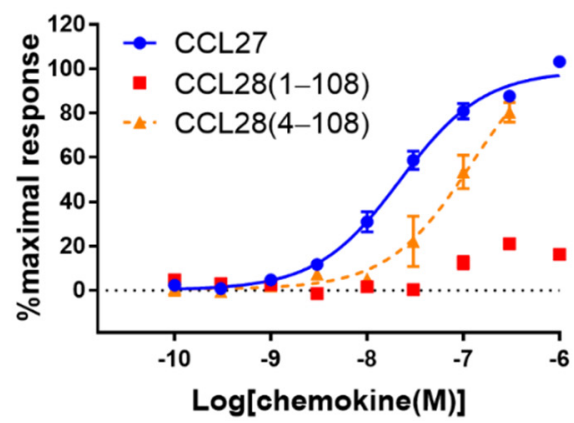

Figure 2. Chemokine ligands differentially stimulate $G$ protein activation via CCR4, CCR7 and CCR10. (a) The principle of the BRET-based G-protein recruitment assay. RLuc8 is fused at the C-terminus tail of GRK3 (GRKct), which is localized to the plasma membrane, and the YFP variant Venus is tagged at the $G \beta_{1} \gamma_{2}$ dimer. Upon activation of a chemokine receptor, the activity of the trimeric $G$ protein complex (G $\alpha$ i2 was overexpressed in this assay) can be detected as the dissociation of G $\alpha$ i and G $\beta \gamma$; the latter binds to the GRK3 C-terminal tail, bringing the YFP and RLuc8 into close proximity and enabling resonance energy transfer after addition of coelenterazine $h$ (coel). (b-d) Chemokine-induced G-protein activation at (b) CCR4 (c) CCR7, and (d) CCR10. A dashed line of best fit is shown in the case that the signal does not reach saturation. The presented data are mean \pm SEM of at least three independent experiments, each performed in triplicate.

\subsection{Cognate Chemokines Stimulate G Protein-Mediated Signaling at CCR7 and CCR10 But Not at CCR4}

Upon binding their cognate ligands, most chemokine receptors undergo conformational changes that result in dissociation of the $G \alpha$ subunit from the $G \beta \gamma$ subunit of heterotrimeric $G$ proteins and downstream suppression of cAMP synthesis catalysed by adenylyl cyclase. For real-time measurement of these processes, we used a FlpIn-CHO cell line stably transfected to express the receptor of interest and then transiently transfected with BRET biosensors to report on $G$ protein activation by the receptor (Figure 2a) or inhibition of forskolin-induced cAMP synthesis (cAMP inhibition, Figure 3a).

In CCR7-expressing cells, CCL19 and CCL21 both stimulated robust responses in the assays of $\mathrm{G}$ protein activation (Figure $2 \mathrm{c}$ and Table 1 ) and cAMP inhibition (Figure $3 \mathrm{c}$ and Table 1). In these assays, both ligands induced similar maximal responses, but CCL19 was more potent by $\sim 15$-fold for $\mathrm{G}$ protein activation and $\sim 9$-fold for cAMP inhibition. This is similar to the relative effects of these ligands in $\beta$-arrestin recruitment at CCR7 (Figure 1c). 


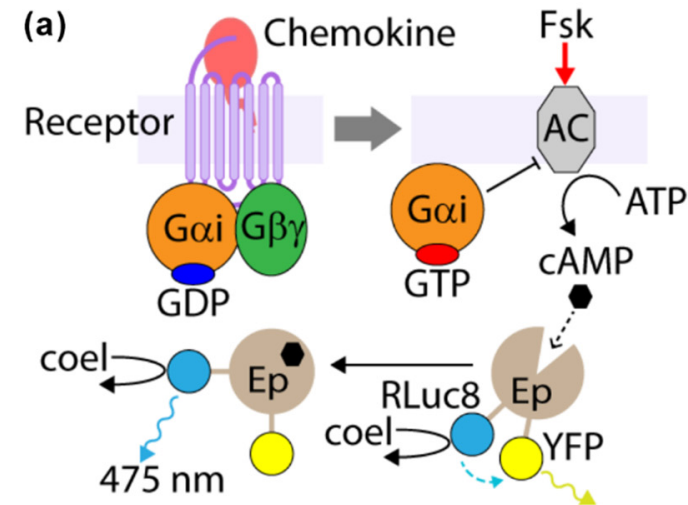

(c)

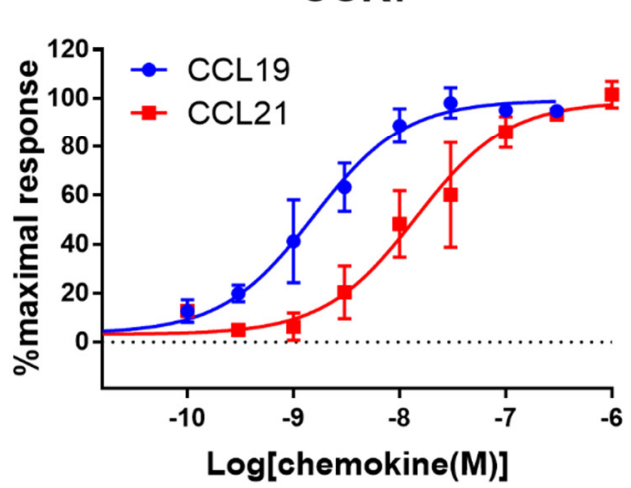

(b)

CCR4

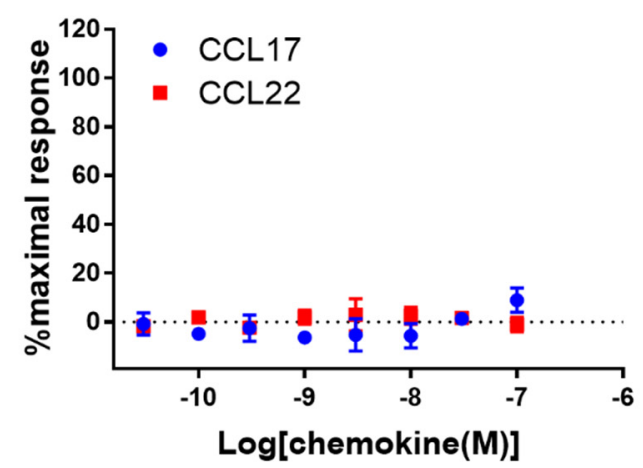

(d)

\section{CCR10}

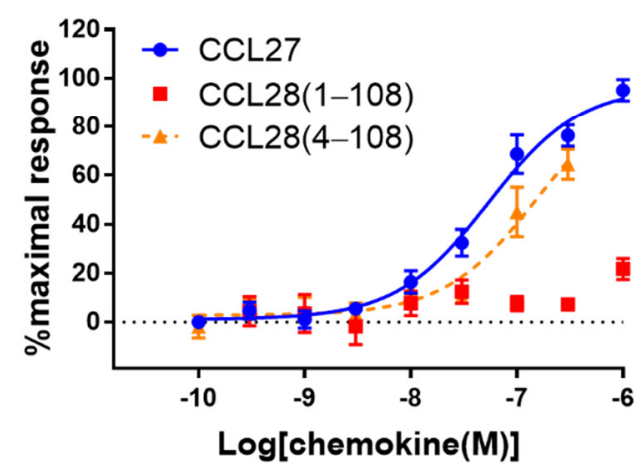

Figure 3. Chemokine ligands differentially inhibit cAMP synthesis via CCR4, CCR7 and CCR10. (a) The principle of the BRET-based cAMP assay. Upon activation of a chemokine receptor, the dissociated Gai/o proteins inhibit the activity of forskolin (Fsk)-stimulated adenylyl cyclase (AC), thus reducing the intracellular concentration of cAMP. The cAMP biosensor CAMYEL is composed of the CAMP binding protein Epac1 (Ep), tagged at opposite ends with RLuc8 and the YFP variant Venus. The conformation of Epac1, within CAMYEL, changes upon binding cAMP and this is used to monitor cellular levels of cAMP by the change of BRET signals. (b-d) Chemokine-induced inhibition of cAMP production via (b) CCR4 (c) CCR7 (d) CCR10. A dashed line of best fit is shown in the case that the signal does not reach saturation. The presented data are mean \pm SEM of at least three independent experiments, each performed in triplicate.

At CCR10, CCL27 and CCL18(4-108) both exhibited robust G protein activation (Figure $2 \mathrm{~d}$ and Table 1) and cAMP inhibition (Figure $3 \mathrm{~d}$ and Table 1). Again, the CCL18(4108) signals were not saturated at the highest concentrations tested, precluding a rigorous comparison of potencies, although CCL18(4-108) appears to be less potent than CCL27 in this assay. Similar to our observations in the $\beta$-arrestin recruitment assay (above), we found that CCL28(1-108) stimulates only very weak $G$ protein activation and cAMP inhibition. Thus, removing the first three amino acids of CCL28 substantially increases both the potency and efficacy (maximum signal) of CCR10 activation in all three signalling readouts.

In stark contrast to the results for CCR7 and CCR10, both cognate chemokines of CCR4 failed to stimulate significant responses in assays of either $G$ protein activation (Figure $2 b$ and Table 1) or cAMP inhibition (Figure $3 \mathrm{~b}$ and Table 1). To ensure that this was not due to lack of receptor expression, we took advantage of the N-terminal cMyc-tag on all receptors used in this study to determine their expression levels by ELISA (Table 2). Relative cell surface expression levels of CCR4, CCR7 and CCR10 in the stable FlpIn-CHO cell lines used for $\mathrm{G}$ protein activation and cAMP inhibition assays were 1:2:30. Although, the FlpIn$\mathrm{CHO}-\mathrm{CCR} 4$ cell line has the lowest receptor expression level among the cell lines used here, the level was well above background and only 2-fold lower than the CCR7 expression level. This slightly lower receptor expression is unlikely to account for the complete lack of $G$ protein-mediated signalling observed. Nevertheless, to investigate this, we constructed 
a naturally occurring CCR4 that is truncated after residue Y331 (CCR4 $\triangle$ C29 [23]. This mutant has been reported to display higher cell surface expression and gain of function in a chemotaxis assay $[24,25]$. As expected, FlpInCHO cells stably expressed $\mathrm{N}$-terminally cMyc-tagged CCR4 $\triangle$ C29 at a level 25-fold higher than full-length CCR4, as assessed by ELISA (Table 2). Despite its higher cell surface expression, CCR4 $\triangle$ C29 was not responsive to up to $100 \mathrm{nM}$ CCL17 or CCL22 in either G protein activation or cAMP inhibition assays (data not shown). We therefore conclude that, when expressed in CHO cells, CCR4 is capable of signalling via $\beta$-arrestin but not via $G$ proteins.

Table 2. Expression levels (\%) of chemokine receptors CCR4, CCR7 and CCR10 in CHO cells ${ }^{1}$.

\begin{tabular}{cc}
\hline Receptor & Normalized Expression Level \\
\hline CCR4 $\triangle$ C29 CCR4 & 100 \\
CCR7 & $4.2 \pm 1.2$ \\
CCR10 & $7.9 \pm 2.0$ \\
\end{tabular}

${ }^{1}$ Cell surface expression levels of cMyc-tagged chemokine receptors in stably transfected FlpIn-CHO cells were determined by cMyc ELISA. Reported levels (mean \pm SEM, $n \geq 3$ ) are arbitrarily normalized as percentage to the corresponding level of C-terminally truncated ( 29 amino acid residues) CCR4 mutant (CCR4 $\triangle$ C29), determined in parallel.

We also evaluated the signalling of CCR4, CCR7 and CCR10 using a reporter gene assay for Nuclear Factor of Activated T Cells (NFAT), which is activated as a consequence of increased cytosolic $\mathrm{Ca}^{2+}$ concentrations (Figure 4a). For this we co-transfected the cells to express $\mathrm{G} \alpha_{15}$, which has previously been shown to couple to a variety of GPCRs originally coupled to G $\alpha$ s or G $\alpha \mathrm{i}$, along with the NFAT reporter gene construct [26]. Treatment of the CCR10-expressing cells with CCL27 or CCL18(4-108) yielded robust responses (Figure 4b and Table 1), although the CCL27 response was approximately 10 -fold more potent than that of CCL28(4-108) ( $p E C_{50}$ values of $8.24 \pm 0.12$ and $7.18 \pm 0.10$, respectively, assuming the same maximal effect). Once again, CCL28(1-108) stimulated only a weak response at the highest concentrations tested. Moreover, treatment of the CCR4- or CCR7-expressing cells with the cognate chemokines of these receptors did not yield any significant response above background in the NFAT reporter assay (data not shown).
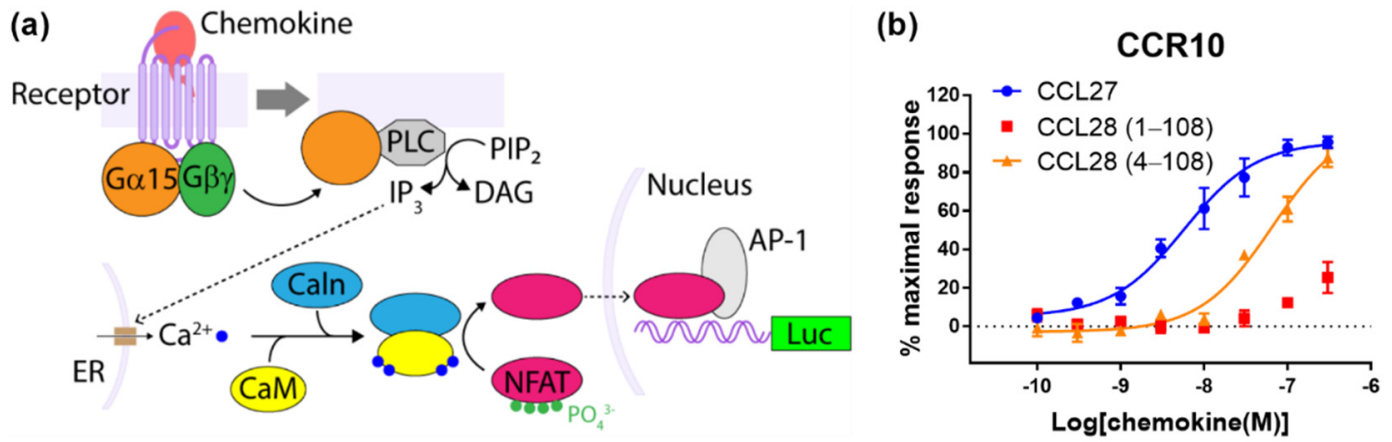

Figure 4. Activation of CCR10 stimulates intracellular $\mathrm{Ca}^{2+}$ mobilization. (a) The principle of the NFAT activation assay. Activation of a chemokine receptor leads to phospholipase C (PLC) activation via the transiently expressed G $\alpha_{15}$, giving rise to downstream release of $\mathrm{Ca}^{2+}$ from the endoplasmic reticulum (ER). Binding of $\mathrm{Ca}^{2+}$ to calmodulin (CaM) then enables activation of the protein phosphatase calcineurin (Caln), which catalyzes dephosphorylation of NFAT, enabling its translocation into the nucleus and transcription of the reporter firefly luciferase gene from an NFAT-sensitive reporter construct. (b) Chemokine-induced NFAT activation via CCR10. The presented data are mean \pm SEM of at least three independent experiments, each performed in triplicate.

Finally, we quantified biased agonism at CCR7 and CCR10 using the Black and Leff operational model $[27,28]$; this was not possible for CCR4 due to the lack of G proteinmediated signaling. None of the possible comparisons provided significant evidence 
of biased agonism between ligands and pathways mediated by either CCR7 or CCR10 (data not shown). Indeed, this result is consistent with the observation that the relative potencies and efficacies of the different ligands at each receptor are similar, irrespective of the signaling readout.

\section{Discussion}

We have presented a systematic analysis of chemokine signaling at the chemokine receptors CCR4, CCR7 and CCR10. We have shown that, in the same expression system, the three receptors mediate different arrays of signaling outcomes. CCR10 was observed to mediate $G$ protein activation, leading to both cAMP inhibition (via $\mathrm{G} \alpha_{\mathrm{i} / \mathrm{o}}$ ) and $\mathrm{Ca}^{2+}$ mobilization (via overexpressed $\mathrm{G} \alpha_{15}$ ), as well as mediating $\beta$-arrestin recruitment. CCR7 could mediate the same downstream outcomes as CCR10 with the exception of $\mathrm{Ca}^{2+}$ mobilization. In contrast, stimulation of CCR4 did not give rise to any $\mathrm{G}$ protein-mediated signaling but clearly induced $\beta$-arrestin recruitment.

At each receptor, the ligands tested were not equivalent in the signaling responses that they induced. However, the nature of these differences varied amongst the receptors and ligands studied. The CCR4 ligands differed primarily in their maximal effect (efficacy) of $\beta$-arrestin recruitment. The CCR7 ligands differed primarily in their potency in all signaling outcomes tested. The CCR10 ligand CCL27 gave robust signals in all assays, whereas CCL28(1-108) gave very weak signals, although the truncated form, CCL28(4-108), gave similar responses to CCL27, with slightly lower potency in most assays. Moreover, in some cases, the ligand-selective effects contrast with those previously reported for the same receptor and ligands. Below, we discuss the details of these effects for each receptor and attempt to rationalize any inconsistencies between studies.

Our observations that, in all assays, CCL19 displayed higher potency but similar efficacy compared to CCL21, are consistent with previous observations. Early studies reported that, when compared at the same concentration $(100 \mathrm{nM})$, CCL19 was more effective than CCL21 in inducing internalization of CCR7 $[19,20]$. Similarly, Zidar et al. reported that, in transfected human embryonic kidney (HEK293) cells, CCL19 promoted stronger $\beta$-arrestin recruitment than CCL21, although they also found that the two ligands stimulated equivalent $G$ protein-mediated responses [7]. Initially, this appeared to suggest biased agonism by these ligands. Indeed, the same authors found that receptor phosphorylation was mediated by different sets of GRKs, which suggests alternative receptor conformations were favored by the two ligands. However, the signaling experiments of Zidar et al. used a single concentration $(100 \mathrm{nM})$ of each ligand. Our data clearly show that, at this concentration, CCL19 elicits much stronger $\beta$-arrestin recruitment than CCL21 (Figure 1c) but both ligands elicit maximal responses in $G$ protein-mediated readouts (Figures $2 c$ and $3 c$ ). This results from the $\beta$-arrestin signal being essentially unamplified, whereas the $G$ protein-mediated signals are somewhat amplified, causing a left-shift of the concentration-response curves [10]. Additionally, consistent with our data, Corbisier et al. found that CCL19 was more potent than CCL21 in both G protein activation and $\beta$-arrestin recruitment (in HEK293 cells), with no significant bias between these ligands and pathways [9]. Two recent studies by Rosenkilde and colleagues have identified features of both the chemokines and CCR7 that contribute to the higher potency of CCL19 $[8,21]$. In particular, the higher potency of CCL19 was suggested to result from differential interactions of the core domains of the two chemokines with extracellular loop 2 of the receptor [8].

Our CCR10 activation data show that "truncated" CCL28(4-108) robustly activates CCR10, whereas "full-length" CCL28(1-108) has minimal activity in all four signaling readouts tested (Figures $1 \mathrm{~d}, 2 \mathrm{~d}, 3 \mathrm{~d}$ and $4 \mathrm{~b}$ ). This raises the question of which form(s) of CCL28 is/are biologically relevant. To the best of our knowledge, there are no available data reporting on the naturally occurring $\mathrm{N}$-terminal sequence or molecular mass of CCL28. However, the SignalP program [29] predicts cleavage of the CCL28 precursor at the sequence SEA-ILP ('-' indicates the cleavage site) to yield CCL28(4-108) with $68 \%$ probability, compared with cleavage at the sequence LHA-SEA to yield CCL28(1-108) with 
only $21 \%$ probability. Based on this prediction and our activity data, we propose that the active biological form is CCL28(4-108), whose N-terminal sequence, up to CC motif, is ILPIASSCC, and that future physiological studies of CCL28 activity mediated by CCR10 should focus on the shorter form of CCL28. We note, however, that CCL28 has also been reported to activate the receptor CCR3 [30] and that the form(s) of CCL28 active at this receptor remain(s) to be determined.

Unlike the CCR7 observations, our CCR10 activation data differ substantially from a previous report. Rajagopal et al. reported that CCL27 stimulated both G protein-mediated and $\beta$-arrestin-recruitment via CCR10, whereas CCL28 stimulated only $G$ protein-mediated signaling; they reported using commercial CCL28(4-108) [4]. This appeared to be a clear example of biased agonism and raised the possibility that differential signaling plays a part in the selectivity of CCL27 and CCL28 for CCR10-expressing T and B lymphocytes, respectively. Our data confirm that CCL27 stimulates both signaling pathways, but differ from the previous report in that we found that CCL28(4-108) also stimulates both G proteinmediated and $\beta$-arrestin recruitment via CCR10 (Figures $1 d, 2 d$ and $3 b$ ), with no evidence of biased agonism between these pathways. We note that the differences in potency observed for CCL27 in the different assays are as expected, due to the different levels of signal amplification/effector coupling in these assays.

On the other hand, we observed a clear difference between the potencies of CCL27 and CCL28(4-108) in the $\mathrm{Ca}^{2+}$-sensitive NFAT reporter assay, suggesting subtle bias between different $G$ protein mediated pathways. We note that this apparent bias may be exaggerated because the NFAT assay is highly amplified in comparison to the other assays used here.

Previous studies have found differences in the responses of CCR4-expressing cells to its two cognate ligands. Activation with CCL22, but not with CCL17, has been reported to desensitize CCR4-expressing murine pre-B cells to subsequent activation by either chemokine [15] and induce rapid internalization of CCR4 in human $\mathrm{T}_{\mathrm{h}} 2$ cells [16]. Consistent with these differences, Ajram et al. observed, using the proprietary Discover $X^{\circledR}$ cell line, that CCL22, but not CCL17, induced $\beta$-arrestin recruitment to CCR4, at chemokine concentrations up to $100 \mathrm{nM} \mathrm{[6].} \mathrm{We} \mathrm{found} \mathrm{that} \mathrm{CCL17} \mathrm{does} \mathrm{induce} \beta$-arrestin recruitment to CCR4 expressed in CHO cells, albeit relatively weakly, at concentrations of $100 \mathrm{nM}$ or higher (Figure 1b). This is in agreement with Viney et al., who reported that $100 \mathrm{nM}$ CCL17 induced significant internalization of CCR4 in the human T cell line Hut78 [17]. These relatively subtle differences in responses to CCL17 may simply reflect the variety of cell types, receptor expression levels and assay formats used in these different studies.

However, there are more substantial differences in the $G$ protein-mediated responses to CCR4 activation observed across different studies. Imai et al. [15] showed robust $\mathrm{Ca}^{2+}$ mobilization in response to both CCL17 and CCL22 in CCR4-transfected murine pre-B (L1.2) cells. They also observed chemotaxis of L1.2-CCR4 and Hut78 cells, with CCL22 inducing higher maximal response than CCL17. GPCR-mediated $\mathrm{Ca}^{2+}$ mobilization and chemotaxis are generally known to be mediated by $\mathrm{G}$ protein signaling, although Lin et al. demonstrated that $\beta$-arrestin 2 also plays a partial but important role in CCR4-mediated chemotaxis of murine $T_{h} 2$ cells [31]. Subsequently, Viney et al. [17] reported that CCL17 and CCL22 displayed equal potency and efficacy in assays of both $\mathrm{Ca}^{2+}$ mobilization (in $\mathrm{T}_{\mathrm{h}} 2$ cells) and chemotaxis (in Hut78 cells or L1.2-CCR4 cells). While CCR4-mediated G protein signaling is apparent in the abovementioned leukocyte cell lines, our results suggest that CCR4 expressed in $\mathrm{CHO}$ cells is unable to transmit signal via $\mathrm{G}$ proteins. The differences in $G$ protein-mediated responses could be due to expression of different isoforms of $G$ proteins in different cell types. Furthermore, CCR4-mediated G protein activity has been detected in isolated membrane preparations from CCR4-expressing $\mathrm{CHO}$ cells, using a $\left[{ }^{35} \mathrm{~S}\right] \mathrm{GTP} \gamma \mathrm{S}$ binding assay $[6,32]$. This suggests that $\mathrm{CHO}$ cells may express soluble factors that suppress $\mathrm{G}$ protein signaling by CCR4 in intact cells.

Irrespective of the mechanisms underlying the selective signaling of CCR4 via $\beta$ arrestin in CHO cells, our results show that, in certain cellular contexts, CCR4 is capable of supporting $\beta$-arrestin recruitment but not $G$ protein-mediated signaling. This effect is 
reminiscent of atypical chemokine receptors, which lack the DRY sequence motif (which is present in CCR4) and therefore do not couple efficiently to $G$ proteins but still support $\beta$-arrestin-mediated events, leading to internalization and scavenging of chemokine ligands [33]. Such scavenging behavior has also been reported for other classical chemokine receptors, such as CCR1 and CCR2 [34-36]. Therefore, we now suggest that CCR4 should be viewed as a versatile receptor whose $G$ protein-mediated (pro-chemotactic) and $\beta$-arrestinmediated (scavenging) functions vary with different cellular contexts and could potentially be regulated by such factors as intracellular binding partners, membrane environment, and post-translational modifications.

Finally, it is noteworthy that stimulation of some chemokine receptors, including both CCR4 and CCR7, has previously been reported to induce not only recruitment of $\beta$-arrestins leading to receptor internalization, but also downstream signaling via $\beta$-arrestin-mediated pathways. Specifically, Lin et al. showed, by genetic deletion of $\beta$-arrestin2, that CCL22induced, CCR4-mediated chemotaxis of Th2 cells was dependent, in part, on a signaling pathway mediated by $\beta$-arrestin2 [31]. In addition, Zidar et al. showed, using $\beta$-arrestin siRNA in HEK293 cells expressing CCR7, that optimal pERK signaling was dependent on $\beta$-arrestin 2 expression but opposed by $\beta$-arrestin1 expression [7]. The current study did not investigate $\beta$-arrestin-mediated signaling per se.

In summary, our systematic study of $G$ protein signaling and $\beta$-arrestin recruitment by cognate chemokines at CCR4, CCR7 and CCR10 highlights significant differences between the intracellular signals elicited. At CCR7, both CCL19 and CCL21 stimulate both G proteinmediated and $\beta$-arrestin-signals, with CCL19 consistently displaying higher potency. At CCR10, CCL27 and CCL28(4-108), but not CCL28(1-108), stimulate G protein-mediated and $\beta$-arrestin-signals, suggesting that CCL28(4-108) is the biologically active form of this chemokine. Finally, at CCR4, both CCL17 and CCL22 selectively activate $\beta$-arrestinmediated pathways, with CCL22 stimulating a substantially stronger signal, suggesting that CCR4 has the potential to act as a scavenger receptor. Comparisons of our results with previous studies further indicate that differential agonism at these receptors may be highly dependent on the cellular context.

\section{Materials and Methods}

\subsection{Materials}

FlpInCHO cells were purchased from Thermo Fisher Scientific. Dulbecco's modified Eagle's medium (DMEM), fetal bovine serum (FBS), penicillin/streptomycin, hygromycin B, and D-luciferin were obtained from Life Technologies (Carlsbad, CA, USA). Coelenterazine $\mathrm{h}$ was purchased from Prolume (Pinetop, AZ, USA). Enzymes and other materials for molecular cloning were sourced from New England Biolabs (Ipswich, MA, USA). Linear $25 \mathrm{kDa}$ polyethyleneimine (PEI) was from Polysciences (Warrington, PA, USA). The human chemokines CCL17, CCL19, CCL21, CCL22, CCL27 and CCL28 (1-108) were supplied by Peprotech (Cranbury, NJ, USA) and human CCL28(4-108) was from BioLegend (San Diego, CA, USA). White 96-well CulturPlates were purchased from PerkinElmer (Boston, MA, USA). All other reagents were purchased from Sigma-Aldrich (St. Louis, MO, USA).

\subsection{Cell Lines Stably Expressing Human CCR4, CCR7, and CCR10}

The cDNAs encoding the human CCR4, CCR7, and CCR10 were obtained from the cDNA Resource Center (www.cDNA.org). A nucleotide sequence encoding C-myc peptide (MEQKLISEEDL) followed by GGATCCGGA (encoding peptide sequence GSG, and including a BamHI site) was added to the $5^{\prime}$ end of the cDNAs and cloned into a modified pcDNA5/FRT/TO vector (the CMV promoter of the original vector is replaced with the EF1 $\alpha$ promoter from $\mathrm{pEF} 4)$.

FlpInCHO cells were maintained in DMEM supplemented with 5\% FBS and $100 \mathrm{u} / \mathrm{mL}$ penicillin and $100 \mu \mathrm{g} / \mathrm{mL}$ streptomycin. For stable transfection, the transfection mixture (4.5 $\mu \mathrm{g}$ pOG44, $0.5 \mu \mathrm{g}$ plasmid containing the receptor construct, and $30 \mu \mathrm{g}$ PEI in $0.5 \mathrm{~mL}$ 
$150 \mathrm{mM} \mathrm{NaCl}$ ) was added into a $10-\mathrm{cm}$ dish containing four million adherent cells. One day after transfection, the cells were diluted and selected with $200 \mu \mathrm{g} / \mathrm{mL}$ hygromycin B.

\section{3. $\beta$-Arrestin Recruitment Assay}

The DNAs encoding Renilla luciferase variant 8 (RLuc8) tagged at the C-termini of CCR4, CCR7, and CCR10 were constructed by PCR amplifying the C-myc-tagged chemokine receptor $\mathrm{cDNAs}$ mentioned above and cloned into a pcDNA3.1-derived plasmid containing the gene encoding Rluc8 [37]. The DNA encoding yellow fluorescent protein (YFP) tagged at the $\mathrm{N}$-terminus of the rat $\beta$-arrestin2 [37] was obtained from Prof. Kevin Pfleger.

The C-myc-CCR4-RLuc8, C-myc-CCR7-RLuc8, and C-myc-CCR10-RLuc8 genes were transiently co-expressed with YFP- $\beta$-arrestin2 in FlpInCHO cells by transfection $(4.5 \mu \mathrm{g}$ receptor-Rluc DNA + $0.5 \mu \mathrm{g}$ YFP- $\beta$-arrestin2 DNA in a $10-\mathrm{cm}$ dish containing four million cells). One day after transfection, the cells were transferred into a white 96-well plate at a density of 50,000 cells/well in $100 \mu \mathrm{L}$ medium and incubated overnight. The cells were stimulated in Hank's balanced salt solution (HBSS) in the presence of chemokine at the indicated concentrations and $5 \mu \mathrm{M}$ coelenterazine-h, with a total assay volume of $80 \mu \mathrm{L}$. The BRET signals were measured at $10 \mathrm{~min}$ after stimulation, using a PHERAstar microplate reader (BMG Labtech, Ortenberg, Germany) to detect the fluorescence at the wavelengths 450-500 $\mathrm{nm}$ and 515-560 $\mathrm{nm}$.

\subsection{G Protein Activation Assay}

FlpInCHO cells stably expressing the chemokine receptors were transiently transfected to express the biosensors for G-protein activation, including $G \alpha_{i 2}, G \beta_{1}$-venus (containing amino acid 156-239 of venus), $\mathrm{G} \gamma_{2}$-venus (containing amino acid 1-155 of venus), and mas-GRK3ct-RLuc8 [38]. One day after transfection, the cells were transferred into a 96-well plate, stimulated and BRET was detected as described above for the $\beta$-arrestin recruitment assay.

\section{5. cAMP Inhibition Assay}

FlpInCHO cells stably expressing the chemokine receptors were transiently transfected to express the biosensors for cAMP, called CAMYEL [39]. One day after transfection, the cells were transferred into a 96-well plate, stimulated and BRET was detected as described above for the $\beta$-arrestin recruitment assay.

\subsection{NFAT Activation Assay}

FlpInCHO cells stably expressing the chemokine receptors were transiently transfected to express $G \alpha_{15}$ (obtained from the cDNA Resource Center) and the NFAT-firefly luciferase reporter gene. The transfer of the transfected cells into white 96-well plates performed the same way as described above. The cells were stimulated for six hours with several concentrations of chemokines, diluted in DMEM at a total volume of $100 \mu \mathrm{L} /$ well. The medium was discarded and firefly luciferase activity was measured in $25 \mu \mathrm{L}$ luciferase reagent $\left(0.8 \mathrm{mM}\right.$ ATP, $230 \mu \mathrm{g} / \mathrm{mL}$ D-luciferin, $18 \mathrm{mM} \mathrm{MgCl}_{2}, 77 \mu \mathrm{M} \mathrm{Na} \mathrm{H}_{2} \mathrm{P}_{2} \mathrm{O}_{7}, 24 \mathrm{mM}$ Tris $-\mathrm{H}_{3} \mathrm{PO}_{4}$ (pH 7.8), 24\% (v/v) glycerol, 1.6\% (v/v) Triton X-100, and $527 \mu \mathrm{M}$ dithiothreitol) using a PHERAstar microplate reader (BMG Labtech, Ortenberg, Germany) at 15 min after the addition of the reagent.

\subsection{Enzyme-Linked Immunosorbent Assay (ELISA)}

The FlpInCHO cells stably expressing the chemokine receptors were transferred to a 48 -well plate (100,000 cells / well in growth medium) and incubated overnight. The cells were washed, fixed with $4 \%$ formaldehyde (in phosphate-buffered saline, PBS) for $30 \mathrm{~min}$, incubated with blocking buffer (PBS in the presence of $1 \%$ bovine serum albumin (BSA)) for $1 \mathrm{~h}$, and then exposed to $400 \mathrm{ng} / \mathrm{mL}$ monoclonal 9E10 anti-Myc (CSIRO, Melbourne, Australia) for $2 \mathrm{~h}$. The cells were washed two times before treated for $1 \mathrm{~h}$ with HRP- 
conjugated rabbit anti-mouse antibody (Sigma Aldrich) that was 1000-fold diluted in PBS supplemented with $1 \%$ BSA. After washing out the secondary antibody, the enzymatic reaction was performed using SigmaFast ${ }^{\mathrm{TM}}$ OPD (Sigma Aldrich) and terminated with $3 \mathrm{M}$ $\mathrm{HCl}$. The $\mathrm{A}_{492}$ was measured in a PHERAstar microplate reader (BMG Labtech, Ortenberg, Germany).

\subsection{Data Analysis and Statistics}

The BRET signal presented in this manuscript is defined the ratio of fluorescence signals measured at 515-560 $\mathrm{nm}$ to those measured at 515-560 nm. For data normalization, $0 \%$ is defined as the activity of a receptor in the absence of any chemokine and $100 \%$ is the maximal effect $\left(E_{\max }\right)$ of CCL22, CCL19, or CCL27 at the relevant receptor (CCR4, CCR7, or CCR10, respectively), with the exception for CCR4 in G protein activation and cAMP inhibition assays. For these latter cases, $0 \%$ is defined as the activity of a receptor in the absence of any chemokine and the maximal effect ( $E_{\max }$ ) of CCL27 at CCR7 is used as a surrogate $100 \%$. The concentration vs. response data were plotted and analyzed with the standard single slope dose-response mathematical model of GraphPad Prism 8.0 (GraphPad Software, CA, USA).

Author Contributions: Conceptualization, H.D.L., J.R.L., M.C. and M.J.S.; Formal analysis, H.D.L.; Methodology, H.D.L., J.R.L., M.C. and M.J.S.; Resources, J.R.L., M.C. and M.J.S.; Writing—original draft, H.D.L. and M.J.S.; Writing—review and editing, H.D.L., J.R.L., M.C. and M.J.S. All authors have read and agreed to the published version of the manuscript.

Funding: This research was funded by National Health and Medical Research Council Project Grant APP1140874 (M.J.S., M.C., J.R.L.).

Institutional Review Board Statement: Not applicable.

Informed Consent Statement: Not applicable.

Conflicts of Interest: The authors declare no conflict of interest.

\section{Abbreviations}

ANOVA analysis of variance

BRET bioluminescence resonance energy transfer

BSA bovine serum albumin

cAMP $\quad 3^{\prime}, 5^{\prime}$-cyclic adenosine monophosphate

CCL C-C motif chemokine ligand

CCR C-C motif chemokine receptor

$\mathrm{CHO} \quad$ Chinese hamster ovary

CXCR C-X-C motif chemokine receptor

DC dendritic cell

DMEM Dulbecco's modified Eagle's medium

$E_{\max }$ maximal response

ELISA enzyme-linked immunosorbent assay

GPCR G protein-coupled receptor

$\mathrm{pEC}_{50} \log _{10}\left(E C_{50}\right)$ where $E C_{50}$ is the concentration (in molar) required for $50 \%$ activation

NFAT nuclear factor of activated T cells

PBS phosphate-buffered saline

PEI polyethyleneimine

PLC phospholipase C

RLuc8 Renilla luciferase 8

$\mathrm{T}_{\mathrm{h}} 2 \quad$ T helper type 2

YFP yellow fluorescent protein 


\section{References}

1. Murphy, P.M. Chemokines and chemokine receptors. In Clinical Immunology E-Book: Principles and Practice, 5th ed.; Rich, R.R.E.A., Ed.; Elsevier Health Sciences: Amsterdam, The Netherlands, 2018; pp. 157-170.

2. Stone, M.J.; Hayward, J.A.; Huang, C.; e Huma, Z.; Sanchez, J. Mechanisms of Regulation of the Chemokine-Receptor Network. Int. J. Mol. Sci. 2017, 18, 342. [CrossRef] [PubMed]

3. Bachelerie, F.; Graham, G.J.; Locati, M.; Mantovani, A.; Murphy, P.M.; Nibbs, R.; Rot, A.; Sozzani, S.; Thelen, M. New nomenclature for atypical chemokine receptors. Nat. Immunol. 2014, 15, 207-208. [CrossRef] [PubMed]

4. Rajagopal, S.; Bassoni, D.L.; Campbell, J.J.; Gerard, N.P.; Gerard, C.; Wehrman, T.S. Biased agonism as a mechanism for differential signaling by chemokine receptors. J. Biol. Chem. 2013, 288, 35039-35048. [CrossRef] [PubMed]

5. Sanchez, J.; Lane, J.R.; Canals, M.; Stone, M.J. Influence of Chemokine N-Terminal Modification on Biased Agonism at the Chemokine Receptor CCR1. Int. J. Mol. Sci. 2019, 20, 2417. [CrossRef] [PubMed]

6. Ajram, L.; Begg, M.; Slack, R.; Cryan, J.; Hall, D.; Hodgson, S.; Ford, A.; Barnes, A.; Swieboda, D.; Mousnier, A.; et al. Internalization of the chemokine receptor CCR4 can be evoked by orthosteric and allosteric receptor antagonists. Eur. J. Pharmacol. 2014, 729, 75-85. [CrossRef] [PubMed]

7. Zidar, D.A.; Violin, J.D.; Whalen, E.J.; Lefkowitz, R.J. Selective engagement of G protein coupled receptor kinases (GRKs) encodes distinct functions of biased ligands. Proc. Natl. Acad. Sci. USA 2009, 106, 9649-9654. [CrossRef]

8. Jorgensen, A.S.; Larsen, O.; Uetz-von Allmen, E.; Luckmann, M.; Legler, D.F.; Frimurer, T.M.; Veldkamp, C.T.; Hjorto, G.M.; Rosenkilde, M.M. Biased Signaling of CCL21 and CCL19 Does Not Rely on N-Terminal Differences, but Markedly on the Chemokine Core Domains and Extracellular Loop 2 of CCR7. Front. Immunol. 2019, 10, 2156. [CrossRef]

9. Corbisier, J.; Gales, C.; Huszagh, A.; Parmentier, M.; Springael, J.Y. Biased signaling at chemokine receptors. J. Biol. Chem. 2015, 290, 9542-9554. [CrossRef] [PubMed]

10. Huma, Z.E.; Sanchez, J.; Lim, H.D.; Bridgford, J.L.; Huang, C.; Parker, B.J.; Pazhamalil, J.G.; Porebski, B.T.; Pfleger, K.D.G.; Lane, J.R.; et al. Key determinants of selective binding and activation by the monocyte chemoattractant proteins at the chemokine receptor CCR2. Sci. Signal. 2017, 10. [CrossRef]

11. Yoshie, O.; Matsushima, K. CCR4 and its ligands: From bench to bedside. Int. Immunol. 2015, 27, 11-20. [CrossRef]

12. Pease, J.E.; Horuk, R. Recent progress in the development of antagonists to the chemokine receptors CCR3 and CCR4. Expert Opin. Drug Discov. 2014, 9, 467-483. [CrossRef] [PubMed]

13. Comerford, I.; Harata-Lee, Y.; Bunting, M.D.; Gregor, C.; Kara, E.E.; McColl, S.R. A myriad of functions and complex regulation of the CCR7/CCL19/CCL21 chemokine axis in the adaptive immune system. Cytokine Growth Factor Rev. 2013, 24, 269-283. [CrossRef]

14. Xiong, N.; Fu, Y.; Hu, S.; Xia, M.; Yang, J. CCR10 and its ligands in regulation of epithelial immunity and diseases. Protein Cell 2012, 3, 571-580. [CrossRef]

15. Imai, T.; Chantry, D.; Raport, C.J.; Wood, C.L.; Nishimura, M.; Godiska, R.; Yoshie, O.; Gray, P.W. Macrophage-derived chemokine is a functional ligand for the CC chemokine receptor 4. J. Biol. Chem. 1998, 273, 1764-1768. [CrossRef]

16. Mariani, M.; Lang, R.; Binda, E.; Panina-Bordignon, P.; D’Ambrosio, D. Dominance of CCL22 over CCL17 in induction of chemokine receptor CCR4 desensitization and internalization on human Th2 cells. Eur. J. Immunol. 2004, 34, 231-240. [CrossRef]

17. Viney, J.M.; Andrew, D.P.; Phillips, R.M.; Meiser, A.; Patel, P.; Lennartz-Walker, M.; Cousins, D.J.; Barton, N.P.; Hall, D.A.; Pease, J.E. Distinct conformations of the chemokine receptor CCR4 with implications for its targeting in allergy. J. Immunol. 2014, 192, 3419-3427. [CrossRef] [PubMed]

18. Hauser, M.A.; Legler, D.F. Common and biased signaling pathways of the chemokine receptor CCR7 elicited by its ligands CCL19 and CCL21 in leukocytes. J. Leukoc. Biol. 2016, 99, 869-882. [CrossRef] [PubMed]

19. Otero, C.; Groettrup, M.; Legler, D.F. Opposite fate of endocytosed CCR7 and its ligands: Recycling versus degradation. J. Immunol. 2006, 177, 2314-2323. [CrossRef] [PubMed]

20. Bardi, G.; Lipp, M.; Baggiolini, M.; Loetscher, P. The T cell chemokine receptor CCR7 is internalized on stimulation with ELC, but not with SLC. Eur. J. Immunol. 2001, 31, 3291-3297. [CrossRef]

21. Hjorto, G.M.; Larsen, O.; Steen, A.; Daugvilaite, V.; Berg, C.; Fares, S.; Hansen, M.; Ali, S.; Rosenkilde, M.M. Differential CCR7 Targeting in Dendritic Cells by Three Naturally Occurring CC-Chemokines. Front. Immunol. 2016, 7, 568. [CrossRef] [PubMed]

22. Gurevich, V.V.; Gurevich, E.V. GPCR Signaling Regulation: The Role of GRKs and Arrestins. Front. Pharmacol. 2019, 10, 125. [CrossRef]

23. Nakagawa, M.; Schmitz, R.; Xiao, W.; Goldman, C.K.; Xu, W.; Yang, Y.; Yu, X.; Waldmann, T.A.; Staudt, L.M. Gain-of-function CCR4 mutations in adult T cell leukemia/lymphoma. J. Exp. Med. 2014, 211, 2497-2505. [CrossRef]

24. Hieshima, K.; Imai, T.; Baba, M.; Shoudai, K.; Ishizuka, K.; Nakagawa, T.; Tsuruta, J.; Takeya, M.; Sakaki, Y.; Takatsuki, K.; et al. A novel human CC chemokine PARC that is most homologous to macrophage-inflammatory protein-1 alpha/LD78 alpha and chemotactic for T lymphocytes, but not for monocytes. J. Immunol. 1997, 159, 1140-1149.

25. Anderson, C.A.; Patel, P.; Viney, J.M.; Phillips, R.M.; Solari, R.; Pease, J.E. A degradatory fate for CCR4 suggests a primary role in Th2 inflammation. J. Leukoc. Biol. 2020, 107, 455-466. [CrossRef] [PubMed]

26. Zhu, T.; Fang, L.Y.; Xie, X. Development of a universal high-throughput calcium assay for G-protein- coupled receptors with promiscuous G-protein Galpha15/16. Acta Pharmacol. Sin. 2008, 29, 507-516. [CrossRef] [PubMed] 
27. Black, J.W.; Leff, P.; Shankley, N.P.; Wood, J. An operational model of pharmacological agonism: The effect of E/[A] curve shape on agonist dissociation constant estimation. Br. J. Pharmacol. 1985, 84, 561-571. [CrossRef] [PubMed]

28. Kenakin, T.; Watson, C.; Muniz-Medina, V.; Christopoulos, A.; Novick, S. A simple method for quantifying functional selectivity and agonist bias. ACS Chem. Neurosci. 2012, 3, 193-203. [CrossRef]

29. Petersen, T.N.; Brunak, S.; von Heijne, G.; Nielsen, H. SignalP 4.0: Discriminating signal peptides from transmembrane regions. Nat. Methods 2011, 8, 785-786. [CrossRef]

30. Pan, J.; Kunkel, E.J.; Gosslar, U.; Lazarus, N.; Langdon, P.; Broadwell, K.; Vierra, M.A.; Genovese, M.C.; Butcher, E.C.; Soler, D. A novel chemokine ligand for CCR10 and CCR3 expressed by epithelial cells in mucosal tissues. J. Immunol. 2000, 165, 2943-2949. [CrossRef]

31. Lin, R.; Choi, Y.H.; Zidar, D.A.; Walker, J.K.L. beta-Arrestin-2-Dependent Signaling Promotes CCR4-mediated Chemotaxis of Murine T-Helper Type 2 Cells. Am. J. Respir. Cell Mol. Biol. 2018, 58, 745-755. [CrossRef] [PubMed]

32. Slack, R.J.; Hall, D.A. Development of operational models of receptor activation including constitutive receptor activity and their use to determine the efficacy of the chemokine CCL17 at the CC chemokine receptor CCR4. Br. J. Pharmacol. 2012, 166, 1774-1792. [CrossRef]

33. Bonecchi, R.; Graham, G.J. Atypical Chemokine Receptors and Their Roles in the Resolution of the Inflammatory Response. Front. Immunol. 2016, 7, 224. [CrossRef] [PubMed]

34. Volpe, S.; Cameroni, E.; Moepps, B.; Thelen, S.; Apuzzo, T.; Thelen, M. CCR2 acts as scavenger for CCL2 during monocyte chemotaxis. PLoS ONE 2012, 7, e37208. [CrossRef] [PubMed]

35. Gilliland, C.T.; Salanga, C.L.; Kawamura, T.; Trejo, J.; Handel, T.M. The chemokine receptor CCR1 is constitutively active, which leads to $\mathrm{G}$ protein-independent, beta-arrestin-mediated internalization. J. Biol. Chem. 2013, 288, 32194-32210. [CrossRef]

36. Zhao, B.N.; Campbell, J.J.; Salanga, C.L.; Ertl, L.S.; Wang, Y.; Yau, S.; Dang, T.; Zeng, Y.; McMahon, J.P.; Krasinski, A.; et al. CCR2Mediated Uptake of Constitutively Produced CCL2: A Mechanism for Regulating Chemokine Levels in the Blood. J. Immunol. 2019, 203, 3157-3165. [CrossRef]

37. Ayoub, M.A.; Zhang, Y.; Kelly, R.S.; See, H.B.; Johnstone, E.K.; McCall, E.A.; Williams, J.H.; Kelly, D.J.; Pfleger, K.D. Functional interaction between angiotensin II receptor type 1 and chemokine (C-C motif) receptor 2 with implications for chronic kidney disease. PLoS ONE 2015, 10, e0119803. [CrossRef]

38. Hollins, B.; Kuravi, S.; Digby, G.J.; Lambert, N.A. The c-terminus of GRK3 indicates rapid dissociation of G protein heterotrimers. Cell. Signal. 2009, 21, 1015-1021. [CrossRef]

39. Jiang, L.I.; Collins, J.; Davis, R.; Lin, K.M.; DeCamp, D.; Roach, T.; Hsueh, R.; Rebres, R.A.; Ross, E.M.; Taussig, R.; et al. Use of a CAMP BRET sensor to characterize a novel regulation of cAMP by the sphingosine 1-phosphate/G13 pathway. J. Biol. Chem. 2007, 282, 10576-10584. [CrossRef] [PubMed] 